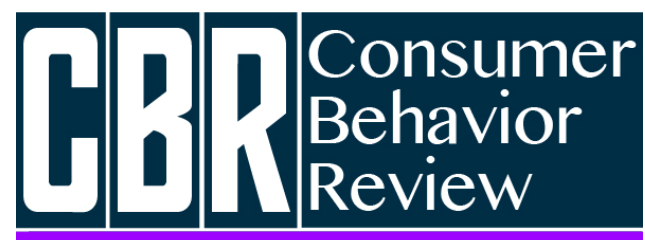

Revista Comportamento do Consumidor
Bevilacqua, S. \& Medeiros, C. R. O. (2017). Análise de denúncias na publicidade comercial e a busca pelo bem estar do consumidor. Consumer Behavior Review, 1(Special Edition), 80-91.
ISSN: 2526-7884

Editor: Prof. Dr. Marconi Freitas da Costa Email da revista: cbr@ufpe.br
Avaliação: Double blind review

Recebido: 06 de julho de 2017

Aceito: 09 de setembro de 2017

\title{
ANÁLISE DE DENÚNCIAS NA PUBLICIDADE COMERCIAL E A BUSCA PELO BEM ESTAR DO CONSUMIDOR
}

\author{
Solon Bevilacqua \\ Cintia Rodrigues de Oliveira Medeiros
}

Solon Bevilacqua é Professor da

Universidade Federal de Goiás - UFG. Email: solbev@gmail.com.

Cintia Rodrigues de Oliveira Medeiros é Professora da Univesidade Federal de Uberlândia - UFU. E-mail:

cintia@fagen.ufu.br.

Este artigo é resultado da pesquisa em estágio pós-doutoral no PPGA/FAGEN/UFU, que recebeu apoio da CAPES. Os autores agracedecem aos avaliadores pelos comentários para melhoria do artigo.

\begin{abstract}
Resumo
A publicidade atua hoje num contexto de choque de ideias; de cobrança por liberdade de expressão e por resultadospoliticamente corretos. Nesse cenário vincado por oportunidades que buscam o bem estar do consumidor, está inserida essa pesquisa, que contempla a análise dos depoimentos de consumidores acerca de comerciais julgados pelo Conselho de Autorregulamentação Publicitária (CONAR). Ao longo deste trabalho foram realizados dois grupos focais, com subsequente análise dos léxicos, do conteúdo e das correspondências dos depoimentos. Ao todo foram relacionados 24 comerciais recentes, considerados desrespeitosos e polêmicos. As considerações indicam que esta amostra de vídeos desrespeita o consumidor (principalmente o público feminino) com cinismo, machismo, miopia, além de provocar insegurança e consumismo. Por conseguinte, esta pesquisa contribui para melhores práticas na busca da qualidade de vida do consumidor, bem como no entendimento de que é possível realizar publicidade comercial, com respeito, bom humor e emoção.

Palavras-chave: Bem Estar, Pesquisa Transformativa do Consumidor, Publicidade.
\end{abstract}

Esta obra está licenciada com uma Licença Creative Commons Atribuição 4.0 Internacional.

\section{INTRODUÇÃO}

Os apelos publicitários atendem ao objetivo de informar as características dos produtos e promovê-los em sua venda. Num primeiro momento a publicidade pode persuadir e gratificar; em outro momento, pode também 
informar novos significados e bem estar ao consumidor. A primeira visão, de cunho mercantilista, ocupa lugar junto aos críticos da sociedade consumista (Jameson, 1991; Baudrillard, 2016); a segunda visão, significacional, é acolhida junto aos agentes publicitários (McCraken, 2015; Douglas \& Isherwood, 2006).

As visões crítica e informacional contribuem sobremaneira para a recente fronteira de pesquisa, intitulada Pesquisa Transformativa do Consumidor (TCR), que sugere investigações acerca do bem-estar e a qualidade de vida do consumidor.

A publicidade, inserida nesse contexto de exigência por boas práticas mercadológicas, demanda um entendimento a partir de um olhar centrado na liberdade de expressão e na prática da ética e respeito pelo consumidor. A TCR encontra aplicação nesse contexto, justamente por se tratar de uma abordagem que objetiva promover um ganho de qualidade de vida e bem-estar entre os envolvidos (Mick, 2006).

Esse olhar, sob o ponto de vista acadêmico, não deve ser considerado uma preocupação recente, visto que na década de 1970 já se buscava o bem estar nas práticas mercadológicas (Bell \& Emory, 1971; Shet \& Parvatlyar, 1995). Entretanto, tal interesse sofre incremento substancial a partir dos anos 2000 com perspectivas como a TCR.

De forma mais restrita, o foco dessa prática recai na inovação dos métodos de pesquisa, em repensar o materialismo, na proteção ao jovem consumidor, em mercados de pobreza, nas ênfases multiculturais e na sustentabilidade dos produtos (Davis \& Pechmann, 2013), bem como o consumo compulsivo, alcoolismo, obesidade e o estudo da vulnerabilidade de alguns grupos específicos (Mick, Pettigrew, Pechmann, \& Ozanne, 2012). Nesse sentido, a TCR afeta as estratégias publicitárias e de marketing, praticamente em toda a sua dimensão.

A publicidade e boa parte dos comerciais estão envolvidos nessa abordagem transformativa, de forma direta ou indireta, afinal, das quatro diretrizes que orientam pesquisadores para práticas de pesquisa ética, uma está diretamente relacionada a publicidade: conhecimento prático; contribuição teórica; aproximação da academia com agentes de transformação social e adoção de estratégias de comunicação alternativa (Mick et al, 2012).

A despeito desse avanço, é perceptível que a prática da boa relação entre anunciantes e consumidores está em descompasso, afinal, no Brasil, por exemplo, prevê-se o controle e restrições publicitárias para 4 áreas de produtos: tabaco, defensivos agrícolas, armas e munições e bebidas alcoólicas (Pastore-Junior, 2014). Ocorre que, na prática, a publicidade expandiu sua atuação além do que é considerado restritivo na regulamentação nacional e internacional. Atualmente, há pouca tolerância para atitudes mercadológicas politicamente incorretas, principalmente, na veiculação de comerciais e campanhas publicitárias em geral. As pesquisas relacionadas à qualidade de vida e bem-estar do consumidor seguem essa tendência.

A partir desse entendimento, é compreensível que a busca da qualidade de vida e do bem-estar do consumidor passam pela função básica da publicidade, que é vender. A publicidade é a ponta da lança do consumismo, de sorte que essa foi concebida para vender, para gerar desejo de consumir, incentivando a compra. Sua existência também prevê a criação de marcas; geração de preferências; divulgação de produtos e incentivo a concorrência entre fabricantes. De outro lado, há grupos organizados que se dedicam a gerar bem estar e acreditam que a sociedade não está preparada para tomar decisões sozinha e precisa deles para orientá-la (Pastore-Junior, 2014).

Diante dessas considerações, este artigo se propõe a analisar depoimentos de consumidores acerca de comerciais denunciados e julgados pelo Conselho de Autorregulamentação Publicitária (CONAR). Para isso, realizou-se uma pesquisa qualitativa, utilizando-se a análise lexical como técnica de análise dos dados. Depois desta introdução, apresenta-se a discussão teórica que subsidia a análise proposta, descrevem-se os procedimentos metodológicos e, em seguida, os resultados são apresentados. As conclusões encerram o artigo.

\section{DISCUSSÃO TEÓRICA}

Os publicitários atuam na construção e repasse de ideias, opiniões, crenças e valores na direção das relações sociais, logo, têm importância na criação e reprodução de 
significados De forma recorrente,esses acreditam que a comunicação é decorrência da existência dos produtos, afinal, sua presença está atrelada à reprodução de imagens existentes, e não à criação de cenários que refletem a sociedade. A existência de um conselho como o CONAR é benéfica a todos os envolvidos, pois regula as práticas éticas, não permitindo a abertura de uma caixa de pandora, onde tudo poderia fugir do controle. Provocar uma discussão entre consumidores e publicitários sugere a abertura dessa caixa (Acevedo, Nohara, Campanário \& Telles, 2009).

Observada a atuação de grupos organizados, como o Conselho Nacional de Autorregulação Publicitária (CONAR), depreende-se que as restrições vão além das boas práticas, concebidas originalmente como aquelas contidas na Constituição Brasileira. 0 CONAR enquadra transgressões consideradas politicamente corretas, como discriminação; estímulo a excessos; identificação publicitária; indução a atividade ilegal; indução a violência; padrões de decência; preconceito; proteção à intimidade; segurança e acidentes; cuidados com o público infantil, responsabilidade social, entre outros. Em 2016, foram 308 processos instaurados e 67 anúncios sustados; em 2015 foram 241 processos instaurados e 44 anúncios sustados - um incremento de $21,75 \%$ e $34,32 \%$, respectivamente (Conselho Brasileiro de Autorregulamentação Publicitária, 2017). Por conseguinte, é possível pensar o CONAR como uma entidade que acompanha a publicidade em seus excessos.

A partir da Tabela 1, é possível depreender que há diversas áreas para autoregulamentação publicitária, representando, também, amplos campos de estudos que objetivem o bem-estar do consumidor e as relações éticas entre os anunciantes, fornecedores e consumidores.

Tabela 1

Áreas da autorregulamentação publicitária

\begin{tabular}{l|r|r|r|r}
\hline Processos Instaurados por queixa de & \multicolumn{1}{c}{2016} & \multicolumn{1}{c}{2015} & \multicolumn{1}{c}{2014} & \multicolumn{1}{c}{2013} \\
\hline Apresentação verdadeira & 39,90 & 30,10 & 33,20 & 26,90 \\
Respeitabilidade & 22,40 & 23,90 & 21,80 & 25,90 \\
Cuidados com o público infantil & 10,10 & 11,70 & 5,90 & 10,60 \\
Responsabilidade social & 6,80 & 12,90 & 7,60 & 7,80 \\
Sustentabilidade & 6,50 & 0,00 & 2,10 & 2,90 \\
Diversos $^{1}$ & 5,50 & 9,20 & 14,30 & 13,90 \\
Padrões de decência $_{\text {Discriminação }}^{3,60}$ & 4,90 & 2,50 & 1,60 \\
Adequação às leis & 3,20 & 3,70 & 3,80 & 4,90 \\
Total (\%) & 1,90 & 3,70 & 8,80 & 5,70 \\
\hline
\end{tabular}

Fonte: Conselho Brasileiro de Autorregulamentação Publicitária (2017a).

Nota. ${ }^{1}$ Discriminação; estímulo a excessos; identificação publicitária...

Os itens de maior presença no rol de queixas por parte dos consumidores se referem ao desrespeito em apresentar um produto que não condiz com a realidade. Logo a seguir, temse a questão de desrespeito à família, grupos étnicos, profissões, entre outros. Esse entendimento, que percorre o caminho do problema em direção à intervenção pelo bemestar, corresponde às premissas de aplicação da TCR. Em outras palavras, a questão deve partir da abordagem a contextos socioculturais e situacionais, e, principalmente, da construção de alianças com consumidores (Mick et al., 2012).
Ainda quanto à Tabela 1 , é possível relacionar alguns problemas dignos de aprofundamentos em TCR. O maior problema evidenciado em CONAR (2017), em suas práticas regulatórias, é o distanciamento entre o previsto e o realizado. É recorrente a discrepância entre o anúncio e seus resultados. Portanto, a questão sugere atenção para três mudanças intrínsecas à pesquisa transformativa: (1) exame de problemas sociais complexos e significativos; (2) escolha de sujeitos de pesquisa que agreguem benefícios sociais aos resultados; (3) divulgação em veículos de comunicação utilizados pelos 
consumidores (Crockett, Downey, Firat, Ozanne, \& Pettigrew, 2013).

É sugerível, portanto, que sob a ótica da TCR, haja, a partir desse quadro, um novo horizonte de pesquisas que priorizem a qualidade de vida do consumidor e práticas salutares de consumo. Quando se trata de uma abordagem como a proposta pela TCR, faz-se importante debruçar-se sobre os estudos que relacionam o outro lado do problema, adicionando, portanto, um olhar plural sobre a publicidade e suas nuances. Tal visão deveria contemplar a dimensão das agências de publicidade e de seus publicitários, entretanto, raros são os estudos que objetivaram abarcar tal problemática.

\section{O bem estar e a liberdade de expressão}

Os publicitários acreditam em dois aspectos que norteiam o entendimento de liberdade nas práticas publicitárias: o que é 'legal é moral' e o governo é permissivo. Se as premissas instaladas não fossem verdadeiras, o próprio governo não iria tolerar o fabrico de armas, munições, bebidas e cigarros. Os produtos estão no mercado e demandam anunciantes e consumidores, portanto, reside nessa discussão a fronteira do legal e do ético (Acevedo, Nohara, Campanário, \& Telles, 2009). Os autores tratam de questões como a prática do 'politicamente correto' (PC), um padrão recorrente nas práticas anticonsumistas. Por conseguinte, o PC parece ter conferido aos tempos contemporâneos um status de sociedade enfadonha.

Há pouca tolerância para o humor em propagandas. Não há mais espaço para piadas com determinados grupos da sociedade brasileira. E esse é um fato recente, ainda não é recorrente existir controle do que vai ser publicizado por parte da população, ficando a cargo de um órgão realizar toda a tarefa. A questão gera uma grande problemática, pois apenas tabaco, defensivos agrícolas, armas e munições estão previstos para serem controlados em comerciais. Os produtos além desses encontram-se em situação de desamparo legal. É recorrente também a questão da falta de maturidade do consumidor brasileiro, que ainda percebe que determinado órgão deve ser o único responsável por cuidar de minorias potencialmente frágeis, como as crianças.
"Surgiu o politicamente correto, e a gente já não podia fazer piada de careca, de gago, de cego, de minoria nenhuma. Para qualquer comercial que você faça já aparecem críticas. A sociedade ficou menos tolerante" (Pastore- Junior, 2014, p. 155). Assim como Dalton Pastore Junior, Washington Oliveto coaduna com a exigência do bom senso no que se refere a peças publicitárias. 0 politicamente correto é adequado, mas coercitivo e sem graça e o exagero do politicamente incorreto é muitas vezes engraçado, mas preconceituoso e grosseiro. 0 ideal seria algo politicamente saudável, em que o senso de humor e a irreverência são mantidos com alegria, educação e bom gosto (Olivetto, 2011).

Se o ideal do politicamente saudável encontra-se em plena construção, a realização diária de escolhas coincide com a existência humana. Uma boa propaganda, ética e saudável auxilia diariamente os consumidores em suas escolhas, por conseguinte, provoca o aprendizado para o uso de inúmeros produtos inovadores. A propaganda é a indústria de ponta da economia criativa, pois boa parte da cidadania se faz pela inclusão de cidadãos no mercado de consumo, por conseguinte, quanto mais o consumidor for informado, melhores serão suas decisões relacionadas ao consumo (Lara, 2014).

Em defesa da função da publicidade, tem-se o argumento de que foi a propaganda brasileira que disseminou o hábito saudável de escovar os dentes por meio dos diversos comerciais de pasta de dente; difundiu hábitos de higiene e limpeza doméstica e propagou o uso de produtos vistos hoje como revolucionários, como é o caso da lavadora de roupas (Lara, 2014). Ainda nessa perspectiva, considera-se saudável que existam vários anunciantes e inúmeras categorias de produtos e de serviços trabalhando com anúncios. Tal aspecto cria uma liberdade financeira, que, por sua vez, viabiliza a liberdade de imprensa. A sustentação desse processo saudável é montada por quem produz; por quem consome e por quem investe (Marques, 2014).

Quanto mais anunciantes, mais independência para os meios de comunicação e mais resistente se torna a democracia das instituições (Pastore-Junior, 2014). A educação representa um elemento-chave nesse contexto, pois oferece ao consumidor subsídios para 
melhor realizar suas escolhas. Não é por acidente que em regimes totalitários não há propagandas comerciais (Schüler, 2014), por conseguinte, reside aqui o maior papel do governo: garantir o respeito à lei e promover um ambiente que estimule as iniciativas (Sabino, 2017; Barbosa, 2014). Afinal, tal discussão existe, pois, ao longo da vida, o consumidor é responsável por uma infinidade de escolhas. É por meio da propaganda que muitas informações chegam ao hábito do consumo, tais como pechinchas, inovações e comparações entre produtos existentes. Consumir, nesse sentido, significa fazer escolhas (Leifert, 2014).

Ocorre que as diretrizes previstas para a publicidade praticada em tempos que a televisão era o maior meio de divulgação já não vigoram. As diretrizes reguladoras para a publicidade vigentes em tempo de Internet rápida são potencialmente fracas, afinal, essas não conseguem limitar as publicações em websites e plataformas de redes sociais.

Tal dualidade que se instala na problemática de um estudo da publicidade brasileira já nasce de uma questão mais antiga, datada da rivalidade entre a escola do pensamento de Frankfurt e do pensamento de Chicago. A escola de Chicago encara o fenômeno consumo e comunicação sob um ponto de vista constituído num ambiente democrático e liberal. Já a escola de Frankfurt percebe o mesmo fenômeno sob a perspectiva de que a comunicação de massas que manipula o povo na busca da satisfação dos interesses das elites. De forma invariável, sob viés marxista, encara a comunicação de massas como um aparelho que dissemina os símbolos, significados, crenças, valores e mitos, serve para a ideologia de dominação. Seria esse o contexto para um cenário informacional, oposto à publicidade centrada em significados (McCraken, 2007).

A publicidade significacional funciona como um dicionário que informa o consumidor dos significantes e significados, como também apresenta um processo constante de experimentação, onde significados são sugeridos, combinados e revisados. 0 consumidor busca, a partir da publicidade, conceitos como o que é ser criança, o que é ser pai, o que é ser de meia idade. São projetos que existem para a definição do self, visto que os indivíduos são livres, mas, ao mesmo tempo, não conseguem atuar livremente, considerando o comprometimento com seus projetos (McCraken, 2015).

Quando consideradas ambas as abordagens, registra-se uma profusão de estudos recentes que contemplam a preocupação em empregarse a TCR no âmbito da publicidade comercial. Estudos centrados em marketing buscaram o entendimento das escolhas sob incerteza de jovens; a propensão ao tabagismo e outras drogas lícitas; entendimento da pobreza; jogos de azar e apostas esportivas; obesidade e sobrepeso; compras compulsivas e endividamento (Yang \& Netemeyer, 2015; Mason, Tanner, Piacentini, Freeman, Anastasia \& Batat, 2013; Blocker, Ruth, Sridharan, Beckwith, Ekici \& Goudie-Hutton, 2013; Martin, Kamins, Pirouz, Davis, Haws \& Mirabito, 2013; Gordon, Gurrieri \& Chapman, 2015; Albuquerque, Brucks, Campbell, Chan, Maimaran, McAlister, \& Nicklaus, 2017; KukarKinney, Scheinbaum \& Schaefers, 2016; Gopaldas, 2014). Por conseguinte, o tema se apresenta emergente, independentemente da abordagem que seja considerada.

\section{O bem estar e a regulamentação publicitária}

Há algum tempo, a publicidade deixou de enfatizar as características dos produtos e passou a destacar os apelos emocionais contidos no consumo de bens e serviços. 0 simbolismo contido no produto evoca certo fetichismo, como se o consumo ali disposto possa provocar aumento da beleza, riqueza ou das conquistas (Munõz \& Martí, 2008). De uma forma ampliada, a publicidade também prevê o aumento da felicidade, pois inibe sentimentos de futilidade e fadiga, preenche a vida vazia, além de preencher as mercadorias de uma aura de romance (Lasch, 1983). Todas essas questões se relacionam com o poder dos publicitários em informar significados à vida dos consumidores, pois trata-se de profissionais que refletem e moldam culturas de consumo, exercendo o papel de intermediários nesse processo de aprendizagem (Drumwright \& Kamal,2016).

Essa é uma prática que dissuade e persuade, e, assim, cria um ambiente de imunidade para o consumidor. Em outras palavras, o consumidor não presta mais atenção à marca $\mathrm{A}$ ou à marca $\mathrm{B}$, mas, sim, na sua 
publicidade. Sendo assim, o consumidor irá comprar, pois entendeu o recado, mesmo que ambas as marcas tiverem sido anuladas. Se criada uma resistência ao imperativo publicitário, por outro lado, haverá um sentido inverso: o consumidor se torna mais sensível ao indicativo da publicidade, ou seja, à sua própria existência como segundo produto de consumo e evidência de uma cultura. Simultaneamente à resistência que se forma contra sua mensagem, essa funciona como persuasor - crê-se, portanto, na publicidade (Baudrillard, 2016).

Produtos como tabaco, bebida alcoólica, armas e munições possuem regulamentação de divulgação específica na maior parte do mundo. Sua publicidade é acompanhada na maioria dos casos por alertas de consumo, aspecto que serviu como contenção para o consumo, principalmente, para o público de faixa etária mais baixa (Gupta \& Gould, 1997). A partir de uma série de estudos correlatos, sabe-se que as variáveis demográficas, tais como idade, renda, religião, domicílio e gênero, são determinantes para a percepção de ética e qualidade nos anúncios publicitários.

Mulheres com maior idade, por exemplo, tendem a perceber aspectos antiéticos em anúncios de bebidas alcoólicas, enquanto uma parcela masculina não tolera anúncios de moda íntima (Waller, 1999). São os problemas que os órgãos reguladores enfrentam, geralmente, associados a desrespeito a algum grupo específico. Os casos mais comuns estão centrados em práticas machistas, preconceituosas e discriminatórias. Esse modelo servia até a disseminação da Internet e sua conseqüente relação com mobilidade urbana. Esse ambiente não prevê facilidade para a gestão das privacidades, mas sabe-se que, nesse contexto, os consumidores são muitas vezes mais positivos e encontram publicidade divertida, provocadora, divertida e informativa (Yaakop \& Hemsley-Brown, 2014). Para alguns autores, esse ambiente divertido torna-se uma ameaça para o bem-estar dos consumidores, principalmente, no que se refere a hábitos alimentares.

É sabido que a população mundial enfrenta problemas em escala ascendente com sobrepeso, bem como com os riscos relacionados à má alimentação. Na mesma proporção, comerciantes investem em publicidade que visam incrementar o consumo de alimentos ricos em açúcar e gordura, que é a antítese de recomendações saudáveis para crianças, adolescentes e adultos (Story \& French, 2004). Ocorre que a alimentação representa apenas uma parcela desse contexto de consumo.

No que se refere à mídia na internet, há um ambiente construído e lúdico para aqueles que se dedicam à pesquisa e ao entretenimento. A estratégia de conferir aos websites uma dose de ludicidade se relaciona a um processo de hibridização do processo comunicativo. Tratase de um processo comunicativo mais participativo (principalmente para a criança), que dificulta a identificação do conteúdo publicitário bem como da intenção persuasiva por trás daquele conteúdo narrativo (Craveiro, 2016). Uma das externalidades negativas observadas nessa ludicidade é o consumismo, principalmente, infantil.

Os riscos dessa exposição ao consumismo a partir da Internet e outros meios acarretam ansiedade; recepção contínua de estímulos; dispersão da atenção, bem como aderência à cultura do consumismo e à consequente dificuldadede lidar com o esvaziamento das boas práticas relacionais. Por outro lado, não é possível defender um consumidor de forma eterna. A revolução digital já se iniciou, sem retorno possível. As tentativas de preservar um indivíduo dessa exposição geraria alguém despreparado para tal realidade (Santi, 2017). Ocorre que é recorrente responsabilizar o produtor ou o consumidor pelos malefícios do consumismo, quando deveria haver um entendimento da ligação que envolve ambos os atores, além de, naturalmente, incluir os meios de publicidade comercial nesse contexto (Ricci, Marinelli, \& Puliti, 2016).

\section{DELINEAMENTO METODOLÓGICO}

A pesquisa em questão enquadra-se como transformativa e centrada no consumidor, em virtude de visar três mudanças intrínsecas à pesquisa transformativa: (1) exame de problemas sociais complexos e significativos; (2) escolha de sujeitos de pesquisa que adicionem benefícios sociais aos resultados; (3) divulgação em veículos de comunicação utilizados pelos consumidores (Crockett et al., 2013). É possível relacionar outras questões vistas como compromissos da TCR, também 
presentes neste estudo: (1) desenvolvimento de métodos adequados ao objetivo; (2) evidenciar contextos socioculturais e situacionais, afinal os anseios dos indivíduos são analisados próximos ao contexto em que se encontram (Mick et al., 2012).

\section{A coleta de dados}

0 corpus da pesquisa compõe-se dos depoimentos de participantes de dois grupos focais, uma técnica apropriada para recolher impressões que os participantes têm sobre determinado objeto, tema, marca ou acontecimento (McDaniel \& Gates, 2003). 0 primeiro grupo focal contou com 12 participantes de ambos os sexos (6 homens e 6 mulheres); o segundo grupo focal contou com participação de 8 mulheres. A idade média dos participantes, em ambos os grupos, foi de 25,6 anos de idade. Para a seleção de participantes, adotou-se a técnica de bola de neve (Vinuto, 2014).

Os grupos focais foram conduzidos com o objetivo de coletar as interpretações dos participantes sobre peças publicitárias denunciadas no CONAR. Para operacionalizar os grupos focais, foram projetadas para os participantes 24 vídeos, divididos em 4 etapas de 6 vídeos. A ideia é que os participantes discutissem os vídeos em bloco, por afinidade de tema. Os vídeos foram selecionados a partir das denúncias realizadas junto ao site CONAR.org.br, (aba/menu 'decisões', 'diretório' e 'casos'). A opção recaiu em utilizar os vídeos dos últimos 10 anos, época ainda recente para lembrança por parte dos participantes. 0 critério de escolha dos vídeos se relaciona a problemática da TCR: busca do bem estar e da qualidade de vida, portanto os vídeos estavam associados a "respeitabilidade". As denúncias feitas ao CONAR foram escolhidas dentre as opções de desrespeito à figura masculina; desrespeito à figura feminina; desrespeito à família; desrespeito à religião; desrespeito à profissão; homofobia e desrespeito à criança. Os vídeos selecionados estavam disponíveis no canal youtube.com.

As sessões foram gravadas e seu conteúdo foi transcrito para análise léxica e de conteúdo.

\section{Técnica de Análise de Dados}

Para a análise do corpus de pesquisa, adotou-se o procedimento encadeado de Análise de Conteúdo e Análise Léxica (Bardin, 1991). De forma sequencial, as variáveis foram relacionadas, a partir de uma tabulação cruzada, e, logo a seguir, analisadas utilizando-se a Análise de Correspondência. As duas variáveis foram criadas a partir da categorização dos depoimentos e das palavras consideradas mais importantes (aquelas mais citadas).

\section{DISCUSSÃO DOS RESULTADOS}

Os participantes (20) demonstraram bom conhecimento e interesse acerca do tema investigado. Dos 176 trechos selecionados para análise, $27(17,3 \%)$ possuíam de 50 a 100 palavras do léxico por resposta (maiores respostas, maior interesse e conhecimento por parte do participante). 0 indicador foi considerado satisfatório, pois serviu de parâmetro de qualidade para o desenvolvimento do estudo.

As participantes mulheres foram mais efetivas em suas respostas a respeito do fator discriminante nos comerciais apresentados. Das 6.284 palavras ditas nos dois grupos focais, $74,14 \%$ estavam relacionadas às mulheres (o segundo grupo focal foi composto unicamente por mulheres); das 693 palavras exclusivas, $70,69 \%$ foram proferidas pelas mulheres; das 319 palavras consideradas comuns, $77,3 \%$ foram ditas também pelas mulheres. 0 uso de maior quantidade de palavras exclusivas e comuns evidencia domínio e interesse pelo assunto.

As propagandas selecionadas envolviam apenas desrespeito com o consumidor. Os participantes perceberam maior desrespeito com relação ao abuso da exibição da figura feminina, visto que o segmento "a mulher", contendo 7 letras foi citado 39 vezes (dentre os 124 selecionados por terem sido citados mais de 5 vezes).

A categorização dos 156 depoimentos foi orientada pelos 10 critérios previstos por Pollay (1987), conforme a seguir (foram utilizadas abreviaturas com três letras para cada critério). A categorização obedeceu ao critério de múltipla resposta (máximo de três alternativas possíveis).

Criação de Estereótipos (EST), (27,3\%); negligência aos valores adequados (VAL), $(24,7 \%)$; miopia aos reais valores da sociedade 
(MIO), (11,9\%); cinismo (CIN), (11,5\%); abuso da sexualidade, (SEX), (7,1\%), materialismo, (MAT), (6,2\%); sugestão de insegurança, (INS), (4,4\%); criação de estado de insatisfação $(4,0 \%)$; processo de status, (STA), $(2,2 \%)$; egoísmo, (EGO), (0,9\%). Com base nessas categorias, é possível observar a exploração de estereótipos e desrespeito aos valores da sociedade. Os comerciais também falham em explorar aspectos da realidade contemporânea, se caracterizando como 'miopia' (Pollay, 1987).

A partir do cruzamento das variáveis 'palavras significativas' (aquelas citadas em maior quantidade) e as 10 categorias (Pollay, 1987) é possível depreender que a variância explicada na Análise de Correspondência (AC) foi considerada baixa $(35,48 \%$ no eixo 1 e, $21,80 \%$ no eixo 2 ). Ocorre que ${ }_{2}$ por se tratar de uma análise centrada em problemática para as Ciências Sociais Aplicadas e pelo caráter exploratório do estudo, pode ser considerada uma variância admissível (Hair, Babin, Money, \& Samouel, 2005).

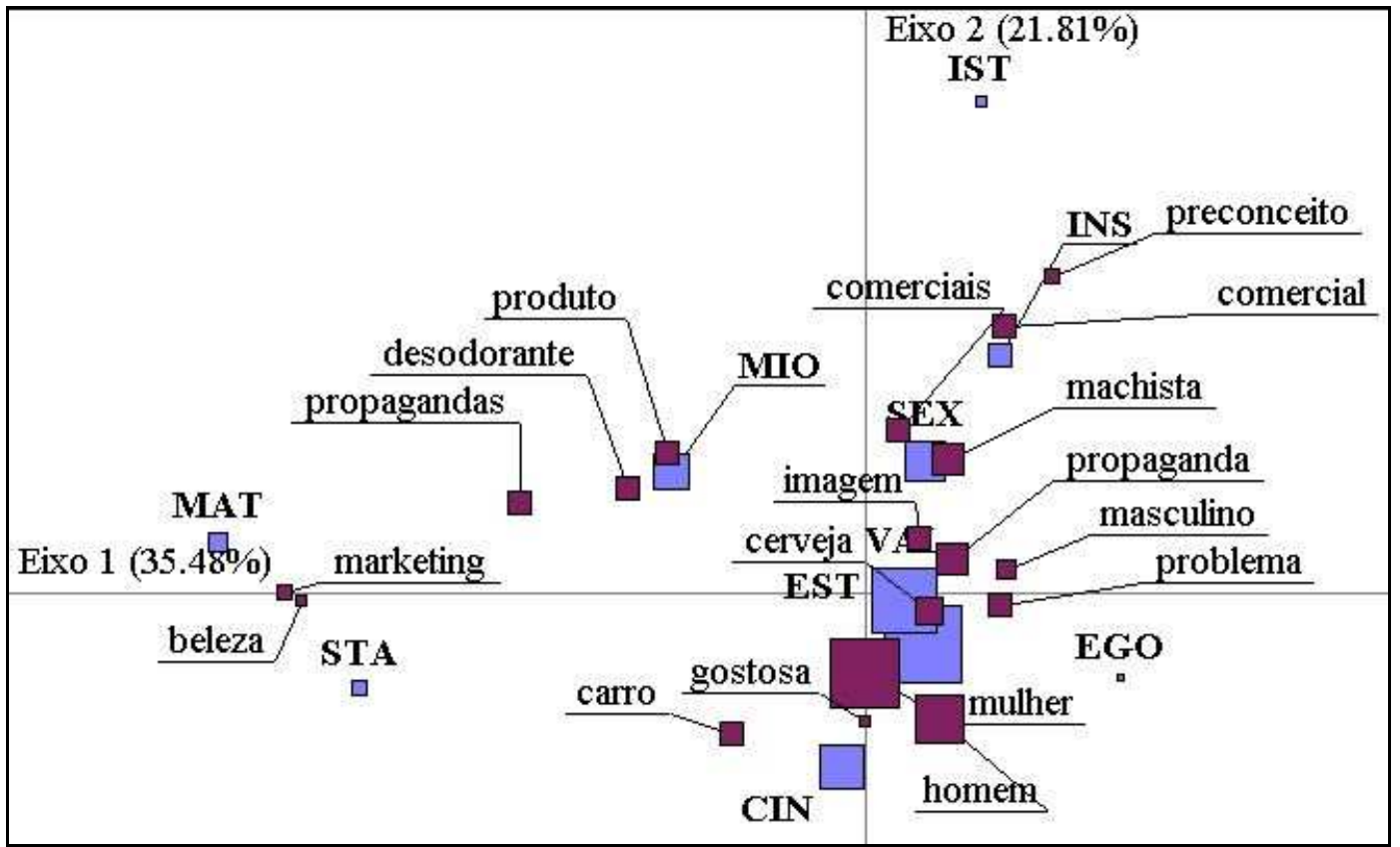

Fonte: Dados da pesquisa.

Figura 1. Análise de Correspondência - palavras expressivas e categorias publicidade.

Primeiro Quadrante [direita-acima]: apresenta uma situação em que se encontram presentes a 'insatisfação', a 'insegurança' e o 'sexismo'. Emergiu da faça dos participantes a questão de que a propaganda trabalha uma ideia de criar um processo de insatisfação e de insegurança, invariavelmente, em torno da imagem feminina. Trata-se do quadrante para as propagandas percebidas como machistas.

Segundo Quadrante [esquerda-acima]: ilustra uma cena em que as propagandas falham ao criar uma visão míope para os produtos anunciados. Entende-se por 'miopia' como a distorção da visão moral que varia desde miopia branda até quase cegueira. Para a miopia em grau elevado, os problemas éticos simplesmente não existem, ou os publicitários são incapazes de percebê-los, pois a 'miopia' moral impede a clara percepção dos problemas éticos (Drumwright \& Murphy, 2004). Nesse quadrante também está presente o materialismo.

Terceiro Quadrante [esquerda-abaixo]: trata- se do agrupamento que reúne o 'status' e o 'cinismo'. Estão presentes as palavras beleza, marketing, carro e gostosa. A questão reside na relação estreita que a posse do carro e da bela mulher provoca. 0 'cinismo' aqui se apresenta como um descaso pelas convenções morais da sociedade, enquanto valores aceitáveis poderiam ser promovidos (Pollay, 1987). 0 quadrante também contempla a distinção e a 
sugestão do status pela posse do que é percebido como belo e valioso (mulheres, prazeres, veículos, entre outros). 0 sucesso dessa prática publicitária tem sido investigado em profusão, inclusive, junto a grupos minoritários de consumidores (Grier \& Deshpandé, 2001; Forehand \& Desphandé, 2001).

Quarto quadrante [direita-abaixo]: esclarece uma extensão do terceiro quadrante, pois alia o materialismo ao egoísmo, centrado na exploração de estereótipos, categoria considerada a mais importante da Análise de Correspondência. Reúne a maior quantidade de citações realizadas pelos participantes. Se registra também nessa relação a questão do descaso com os valores da sociedade, principalmente, com o casamento e família. Os participantes entendem que é recorrente estereotipar homens e mulheres em suas atividades rotineiras.

De uma forma ampliada, observa-se que emergem das interpretações dos participantes sobre as peças denunciadas as seguintes questões: [1] o machismo nos comerciais é visto como uma forma de preconceito e resulta em um processo de insatisfação, que pode ser ainda uma tática para provocar uma situação de desamparo no consumidor (carência versus desejo). 0 machismo funciona nesse aspecto como uma prática de enaltecer a imagem masculina e produzir um padrão de exploração da imagem da mulher, relacionada à cerveja (não ao carro e a desodorante); [2] o cinismo está intrinsecamente relacionado à imagem do carro, nesse caso, se trata de uma categoria que prevê uma afronta às questões morais; [3] a miopia relaciona-se a produtos como desodorante, ou seja, comerciais que foram percebidos como 'rasos' ou 'desfocados' de seu real objetivo; [4] o status e o materialismo posicionam-se na mesma dimensão, ambos associados à beleza e ao marketing.

Em alguns comerciais, como é o caso de produtos para limpeza (palha de aço, alvejante, detergente, desinfetante, entre outros), foi percebida a estratégia de valorização da imagem feminina, todavia, conforme as interpretações dos participantes, foi uma tentativa infrutífera. 0 anunciante não logrou realizar seus objetivos, que consistiam em enaltecer a atividades daquele(a) que trabalha na limpeza doméstica. Práticas como essas foram enquadradas como 'estereótipo'; 'cinismo' e 'miopia'. A partir do depoimento da participante ' $A$ ', transcrito a seguir, é possível perceber a falha dessa estratégia.

\begin{abstract}
"Voltando um pouco nesse caso, por mais que queira mostrar que o homem tem que fazer as atividades domésticas, não é uma ajuda, isso dá uma raiva muito grande, é trabalho de todo mundo que está vivendo numa casa, e tem que manter ela limpa e organizada é tarefa de todo mundo, mas é aquela divisão sexual das tarefas e elas reforçam nesse sentido ali ainda, ao mesmo tempo que tentam passar que somos iguais, igualdade homem-mulher, elas acabam reforçando essa questão da mulher ser melhor na casa do que o homem, tanto que elas falam que elas são divas e os homens são devagar; aí está fortalecendo mais ainda essa questão" (Participante A).
\end{abstract}

Junto ao centro do gráfico (Figura 1), posição que apresenta uma situação não discriminante para ambas as variáveis, é possível tecer alguns apontamentos sobre os 'valores' e o 'estereótipo'. Nesse agrupamento, encontram-se também as palavras 'cerveja', 'homem' e 'imagem'. O agrupamento deve ser considerado não discriminante em virtude de que tais aspectos são esperados para um comercial de cerveja, ou seja, seria justamente isso a ser apresentado quando de uma peça publicitária. Essa tem sido uma estratégia clássica na história da propaganda mundial para cerveja: expor com mais frequência rostos masculinos e corpos femininos em trajes de banho (Hall \& Crum, 1990; Rossiter \& Percy, 1980).

\section{CONCLUSÃO}

Esse contexto apresenta publicitários que reivindicam liberdade de expressão e defendem a publicidade como uma ação que instrui e vende produtos já existentes. A publicidade não cria produtos e, se está previsto proibir, que seja proibida a fabricação e não a divulgação. No outro extremo estão grupos de consumidores que se sentem prejudicados com o desrespeito, pois são alvo de machismo, homofobia, piadas discriminatórias e atentado aos valores das famílias (Ramos, 2015). Para ambos os atores, existe o CONAR como um órgão que regula as boas práticas e confere a qualidade de vida 
necessária a todo esse contexto.

Nessa breve exposição, é possível instalar a 'Pesquisa Transformativa do Consumidor' como uma abordagem que provê suporte ao pesquisador e demais envolvidos a desenvolver as boas práticas de consumo - o objetivo é a busca pelo bem estar e a qualidade de vida. Dessa forma, pesquisas como esta, são capazes de identificar questões que sugerem justamente tais atitudes de valor.

Foram identificadas questões que sugerem maior atenção aos preceitos éticos e sustentáveis no consumo. De forma recorrente, o corpo feminino é explorado e constantemente associado a bebidas e automóveis, enquanto o rosto (e não o corpo) dos homens é visto em situações estereotipadas de poder e status. 0 machismo é percebido de várias formas, inclusive, em comerciais que primam por enaltecer a mulher. Tratam-se de dois aspectos também percebidos pelos participantes: miopia e o cinismo.

Tais questões apresentam-se no gráfico (Figura1) de AC como não discriminante (quando as relações entre as variáveis estão localizadas ao centro do gráfico), um quadro que serve de alerta para a melhora das boas práticas, afinal aí reside um cenário em que o desrespeito já está imbricado no contexto da publicidade brasileira; o uso e abuso dos estereótipos funciona como uma regra dos anunciantes e publicitários. Esse é o contexto informacional previsto por McCraken (2007; 2015).

A trajetória da publicidade brasileira sugere uma prática centrada no resgate da transmissão de significados; na educação e na busca por transmissões de valores. Essa seria também uma percepção dos participantes. Esse olhar sobre o problema de pesquisa também indica uma miopia por parte das empresas anunciante, que não observaram as mudanças que a sociedade vivencia, principalmente nos papéis exercidos na família. Sem dúvida os papéis estáticos (pai, filho, mãe, provedor da casa, chefe de família, trabalhador...) se alteraram substancialmente, sem que, no entanto, as peças publicitárias fizessem o devido acompanhamento.

Em alguns depoimentos, os participantes da pesquisa informam que há espaço para a liberdade de expressão e o respeito, bem como para o humor e a emoção. Há também espaço para se evitar a instalação de uma sensação de 'insegurança' e 'desamparo' (como por exemplo, 'veja você antes e depois'; 'bonita e feia'; 'rica e pobre', ou ainda, 'se você não possuir. não será').

Registra-se uma agenda para pesquisas futuras, que considerem abordagens qualitativas, quantitativas e mistas. Por exemplo, estudos que contemplem amostras maiores e representativas, que possibilitem análises estatísticas multivariadas, bem como experimentos que identifiquem sugestões e percepções a partir de comerciais tidos como reprodutores de estereótipos. Ainda, sugeremse análises qualitativas das peças publicitárias que utilizem a análise crítica de discurso, de modo a revelar ideologias e a reprodução de discursos hegemônicos. Há espaço também para estudos bibliométricos, que sirvam como base para elaboração de referenciais teóricos sobre o tema.

Contribuições Gerenciais: almeja-se que a 'Pesquisa Transformativa do Consumidor' entenda a importância de que os significados e informações contidas nas propagandas sejam estudadas, podendo contemplar o teor das denúncias realizadas em órgãos de autoregulamentação; consumidores e anunciantes. A ideia é um contexto permeado pela ética, bemestar e qualidade de vida dos consumidores. As peças publicitárias devem ser ajustadas para contemplar a moderna sociedade brasileira, com seus novos papéis remodelados $\mathrm{e}$ orientados à conjuntura econômica mundial.

Há espaço para a fuga da receita estereotipada. Há casos recentes de comerciais norte-americanos, primorosamente elaborados, que conseguem emocionar ou fazer rir, como é o caso da sequência "puppy love" (Budweiser), https://youtu.be/hck3cXzg4_M, ou ainda, "retratos da real beleza" (Dove), https://youtu.be/Il0nz0LHbcM. Torna-se importante lembrar, que, há cerca de 30 anos, os publicitários brasileiros conquistavam todos os prêmios mundiais de propaganda, com peças como "o primeiro sutiã" (Valiseire).

Contribuições Teóricas: o estudo contribui para a teoria clássica da 'Pesquisa Transformativa do Consumidor' quando fornece recursos práticos para estudos como Mick (2006), Bell \& Emory (1971) e Shet \& Parvatlyar (1995), bem como demais teorias que envolvam cultura e significados de 
consumo.

\section{REFERÊNCIAS}

Albuquerque, P., Brucks, M. L., Campbell, M. C., Chan, K., Maimaran, M., McAlister, A. R., \& Nicklaus, S. (2017). Persuading children: Long-lasting influences on children's food consideration sets, choices, and consumption. INSEAD Working Paper, 17.

Acevedo, C. R., Nohara, J. J., Campanário, M. D., \& Telles, C. C. (2009). Ética da propaganda sob o olhar dos publicitários. RAE - eletrônica, 8(1), 100-120.

Barbosa, F. (2014). Democracia, liberdade de expressão e livre iniciativa. In: F. Schüller, \& P. Blanco. Pensadores da Liberdade: em torno de um conceito (pp. 35-39). São Paulo: Palavra Aberta.

Bardin, L. (1991). Análisis de contenido. Madrid: Ediciones Akal.

Baudrillard, J. (2016). The consumer society: Myths and structures. Londong: Sage Publishing.

Bell, M., \& Emory, W. (1971). The faltering marketing concept. The Journal of Marketing, 37-42.

Blocker, C. P., Ruth, J. A., Sridharan, S., Beckwith, C., Ekici, A., Goudie-Hutton, M. \& Varman, R. (2013). Understanding poverty and promoting poverty alleviation through transformative consumer research. Journal of Business Research, 66(8), 1195-1202.

Bourdieu, P. (1989). O poder simbólico. Rio de Janeiro: Difel/Bertrand.

Bourdieu, P. (2010). A dominação masculina. São Paulo: Bertrand Brasil.

Bourdieu, P., \& Miceli, S. (1974). A economia das trocas simbólicas. São Paulo: Perspectiva.

Conselho Brasileiro de Autorregulamentação Publicitária. (6 de 6 de 2017). CONAR. Fonte: CONAR: www.CONAR.org.br

Conselho Brasileiro de Autorregulamentação Publicitária. (6 de 6 de 2017a). Boletim do CONAR - edição 212 - Março 201. Fonte: CONAR: www.CONAR.org.br

Craveiro, P. S. (2016). Publicidade e infância: estratégias persuasivas direcionadas para crianças na internet. Culturas Midiáticas, 9(1).

Crockett, D., Downey, H., Firat, A., Ozanne, J., \& Pettigrew, S. (2013). Conceptualizing a transformative research agenda. Journal of Business Research, 66(8), 1171-1178.

Davis, B., \& Pechmann, C. (2013). Introduction to the Special Issue on transformative consumer research: Developing theory to mobilize efforts that improve consumer and societal well-being. Journal of Business Research, 66(8), 1168-1170.
Douglas, M., \& Isherwood, B. (2006). The world of goods. New York: Basic.

Drumwright, M., \& Kamal, S. (2016). Habitus, doxa e ética: idéias de propaganda em mercados emergentes no Oriente Médio e África do Norte. Consumption Markets \& Culture, 19(2), 172-205.

Drumwright, M., \& Murphy, P. (2004). How advertising practitioners view ethics: moral muteness, moral myopia, and moral imaginatio. Journal of Advertising, 33(2), 7-24.

Forehand, M. R., \& Desphandé, R. (2001). What we see makes us who we are: Priming ethnic selfawareness and advertising response. Journal of Marketing Research, 38(3), 336-348.

Gopaldas, A. (2014). Marketplace sentiments. Journal of Consumer Research, 41(4), 995-1014.

Gopaldas, A. (2014). Marketplace sentiments. Journal of Consumer Research, 41(4), 995-1014.

Gordon, R., Gurrieri, L., \& Chapman, M. (2015). Broadening an understanding of problem gambling: The lifestyle consumption community of sports betting. Journal of Business Research, 68(10), 2164-2172.

Grier, S. A., \& Deshpandé, R. (2001). Social dimensions of consumer distinctiveness: The influence of social status on group identity and advertising persuasion. Journal of Marketing Research, 38(2), 216-224.

Gupta, P., \& Gould, S. (1997). Consumers' perceptions of the ethics and acceptability of product placements in movies: Product category and individual differences. Journal of Current Issues \& Research in Advertising, 37(1), 37-50.

Hair, J., Babin, B., Money, A., \& Samouel, P. (2005). Fundamentos de métodos de pesquisa em administração. 2005. Bookman Companhia.

Hall, C. I., \& Crum, M. (1990). Women and "bodyisms" in television beer commercials. Sex Roles, 31(5), 339-337.

Jameson, F. (1991). Postmodernism, or, the cultural logic of late capitalism. Duke University Press.

Kukar-Kinney, M., Scheinbaum, A. C., \& Schaefers, T. (2016). Compulsive buying in online daily deal settings: An investigation of motivations and contextual elements. Journal of Business Research, 69(2), 691-699.

Lara, L. (2014). Propaganda e Liberdade. In: F. L. Schüller, \& P. Blanco. Pensadores da Liberdade: em torno de um conceito (pp. 86-89). São Paulo: Palavra Aberta.

Lasch, C. (1983). A cultura do narcisismo: a vida americana numa era de esperanças em declínio. São Paulo: Imago.

Marques, 0. (2014). Liberdade de expressão comercial e direito de escolha. In: F. Schüller, \& P. Blanco. Pensadores da Liberdade: em 
torno de um conceito (pp. 117-125). São Paulo: Palavra Aberta.

Martin, I. M., Kamins, M. A., Pirouz, D. M., Davis, S. W., Haws, K. L., Mirabito, A. M. \& Grover, A. (2013). On the road to addiction: The facilitative and preventive roles of marketing cues. Journal of Business Research, 66(8), 1219-1226.

Mason, M. J., Tanner, J. F., Piacentini, M., Freeman, D., Anastasia, T., Batat, W. \& Rangan, P. (2013). Advancing a participatory approach for youth risk behavior: Foundations, distinctions, and research directions. Journal of Business Research, 66(8), 1235-1241.

Mason, M. J., Tanner, J. F., Piacentini, M., Freeman, D., Anastasia, T., Batat, W. \& Rangan, P. (2013). Advancing a participatory approach for youth risk behavior: Foundations, distinctions, and research directions. Journal of Business Research, 66(8), 1235-1241.

McCraken, G. (2007). Cultura e consumo: uma explicação teórica da estrutura e do movimento do significado cultural dos bens de consumo. Revista de Administração de Empresas, 47(1), 99-115.

McCraken, G. (2015). Cultura \& consumo II. Rio de Janeiro: Mauad.

Mick, D. (2006). Meaning and mattering through transformative consumer research. Advances in Consumer Research, 33(1), 1-4.

Mick, D. G., Pettigrew, S., Pechmann, C. C., \& Ozanne, J. L. (2012). Transformative consumer research for personal and collective well-being. New York: Routledge.

Munõz, P., \& Martí, J. (2008). Engagement marketing. Una nueva publicidad para un marketing de compromiso. Madrid: Pearson Educación.

Olivetto, W. (2011). Publicidade também é cultura. In: CONAR, autorregulamentação e liberdade de expressão (pp. 7-12). São Paulo: CONAR Conselho Nacional de Autorregulamentação Publicitária.

Pastore Junior, D. (2014). A sociedade ficou mais chata. Sumários Revista da ESPM, 148-158.

Pastore Junior, D. (2014). Publicidade: direito de escolha e responsabilidade empresarial. In: F. Schüller, \& P. Blanco. Pensadores da liberdade: em torno de um conceito (pp. 25-27). São Paulo: Palavra Aberta.

Pollay, R. (1987). On the Value of Reflections on the Values in" The Distorted Mirror". The Journal of Marketing, 104-110.

Ricci, C., Marinelli, N., \& Puliti, L. (2016). The Consumer as Citizen: The Role of Ethics for a Sustainable Consumption. Agriculture and Agricultural Science Procedia, 8, 395-401.

Rossiter, J., \& Percy, L. (1980). Attitude change through visual imagery in advertising. Journal of Advertising, 9(2), 10-16.

Sabino, M. (2017). Liberdade de expressão comercial: potência de cidadania. In: P. Blanco. Pensadores da Liberdade: liberdade e cidadania (pp. 116-126). São Paulo: Palavra Aberta.

Santi, P. d. (2017). Sobre o uso da Internet por crianças. Em P. Blanco. Pensadores da liberdade, liberdade e cidadania (pp. 142-152). São Paulo: Palavra Aberta.

Schüler, F. (2014). 0 século da Liberdade. In: F. Schüler, \& P. Blanco. Pensadores da liberdade: em torno de um conceito (pp. 37-39). São Paulo: Palavra Aberta.

Shet, J. N., \& Parvatlyar, A. (1995). Relationship marketing in consumer markets: Antecedents and consequences. Journal of the Academy of marketing Science, 23(4), 255-271.

Story, M., \& French, S. (2004). Food advertising and marketing directed at children and adolescents in the US. International Journal of Behavioral Nutrition and Physical Activity, $1(1), 3$.

Waller, D. (1999). Attitudes towards offensive advertising: an Australian study. Journal of Consumer Marketing, 16(3), 288-295.

Yaakop, A., \& Hemsley-Brown, J. (2014). Attitudes toward specific advertising media (AM): Informative or manipulative? Asian Social Science, 10(7), 200.

Yang, Z., \& Netemeyer, R. G. (2015). Differential effects of parenting strategies on child smoking trajectories: A longitudinal assessment over twelve years. Journal of Business Research, 68(6), 1273-1282.

\section{Analysis of Complaints in Commercial Advertising and the Search for the Consumer's Well-Being}

Abstract: Type or paste your advertising operates today in a context of clash of ideas; of collection for freedom of expression and for politically correct results. In this scenario, highlighted by opportunities that seek the consumer's well-being, this research is inserted, which includes the analysis of consumer testimony about commercials judged by the Conselho de Autorregulamentação Publicitária (CONAR). Throughout this work two focus groups were realized, with subsequent analysis of the lexicons, content and correspondences of the testimonies. In all, 24 recent commercials were considered disrespectful and 
controversial. The considerations indicate that this sample of videos disrespects the consumer (mainly the female audience) with cynicism, sexism, myopia, besides provoking insecurity and consumerism. Therefore, this research contributes to better practices in the quest for consumer quality of life, as well as in the understanding that is possible to conduct commercial advertising with respect, good humor and emotion.

Keywords: Welfare, Transformative Consumer Research, Advertising. 